\title{
UMA PERSPECTIVA DOS RESÍDUOS DE TINTAS E VERNIZES NO MUNICÍPIO DE SOBRADINHO/RS
}

A perspective about paints and varnishes' solid wastes in Sobradinho/RS

\author{
Hedelvan Emerson Fardin'1, Jorge Orlando Cuéllar Noguera²
}

\author{
${ }^{1}$ Especialização em Educação Ambiental - UFSM \\ 2 Doutorado em Engenharia de Produção, Departamento de Engenharia Química, UFSM, Santa Maria, RS, Brasil.
}

\begin{abstract}
Resumo
Esta pesquisa apresenta uma análise dos resíduos sólidos de tintas e vernizes no município de Sobradinho/RS. Busca-se identificar destinações dos resíduos desses materiais construtivos que podem ser tomadas pelos geradores sem danos ao Meio Ambiente. Concomitantemente, busca-se apresentar os riscos característicos do descarte incoerente desses resíduos, com intuito de conscientizar os geradores a não destinar seus resíduos de tintas ou embalagens a meios de reciclagem de forma divergente àquela esperada pela manutenção de um bom contexto ambiental. Para composição do panorama desses resíduos no município, foi realizada uma pesquisa bibliográfica com intuito de conceituar o tema e uma pesquisa de levantamento de dados nas lojas que vendem tintas e vernizes em Sobradinho, com intuito de aferir o quanto que os colaboradores desses estabelecimentos sabem informar seus clientes a respeito da periculosidade de tintas e vernizes ao Meio Ambiente.
\end{abstract}

Palavras-chave: Resíduos sólidos. Tintas e vernizes. Meio Ambiente.

\begin{abstract}
This research presents an analysis of paints and varnishes' solid wastes in Sobradinho, RS. It aims to identify the destinations of wastes from these constructive materials that may be taken by the generators without harming the environment. Concurrently, we aim to present the characteristic risks caused by incoherent reject of these wastes, with the purpose to educate generators to avoid the destination of their paints' wastes or packages to recycling means in different ways to that expected for the maintenance of good environmental context. To create the panorama of these wastes in Sobradinho, a literature search was done in order to conceptualize the monograph's subject and subsequently, a data survey research in stores that sell paint and varnish in the city, aiming to assess how the employees from these establishments know how to inform their customers about the danger of paints and varnishes for the environment.
\end{abstract}

Keywords: Solid wastes. Paints and varnishes. Environment. 


\section{Introdução}

Sobradinho é uma cidade interiorana da região central do estado do Rio Grande do Sul, possui em torno de quatorze mil habitantes e tem estado em constante desenvolvimento construtivo nos últimos anos, não se excluindo da situação habitacional de diversas cidades brasileiras. Devido a isso, percebese uma forte requisição da indústria construtiva civil e que, consequentemente, por ser a maior geradora de resíduos sólidos, tem produzido uma carga residual sobre o Meio Ambiente que nem sempre recebe a destinação correta que os geradores deveriam dar.

Em decorrência disso, quando avistamos os mais diversos trabalhos da construção civil em uma cidade nem sempre temos ideia do quanto de material construtivo foi requerido pelo empreendimento e simplesmente supunha-se que "foi muito", o que não deixa de ser verdade, mas que refuta a mensuração da quantidade de resíduos produzidos ou desperdiçados para que a dita obra estivesse bela aos mais curiosos olhares. Logo, uma visão menos obtusa a estes empreendimentos é necessária para a manutenção de uma sociedade consciente de seus efeitos sobre o Meio Ambiente.

Objetivando assim, rever algumas ações tomadas de forma empírica pelos sobradinhenses quanto ao descarte irregular de resíduos de tintas ou vernizes e suas embalagens, a pesquisa apresenta perspectivas de colaboradores de lojas de Sobradinho que vendem estes materiais construtivos. Ou seja, um panorama dos resíduos de materiais de pintura nesse município será delimitado a partir dos intermediários dos geradores, buscando apresentar o quanto que estes denotam reponsabilidade sobre os volumes de resíduos sólidos advindos de materiais construtivos.

Em contraponto, sob ações educativas ambientais, busca-se modificar alguns ideais tidos como corretos no contexto socioambiental sobradinhense acerca dos resíduos sólidos de tintas e vernizes imobiliários. A considerar que inúmeros impactos ambientais de pequeno porte podem ser efeito da inexatidão informativa que muitos colaboradores utilizam em seus ambientes de trabalho e que, via de regra, alongam-se a seus clientes, os de fato, geradores de resíduos sólidos.

\section{Abordagem Teórico-Metodológica}

A pesquisa caracteriza-se por ser aplicada, que gera conhecimentos para aplicação prática, dirigidos à solução de problemas específicos, envolvendo interesses locais sobre a construção do conhecimento acerca de tintas e vernizes como materiais construtivos e a compreensão dos efeitos de seus resíduos sólidos sobre o Meio Ambiente.

No segmento da pesquisa bibliográfica, foram consideradas a cientificidade e veracidade de textos consoantes às normas e legislações que regem estes tipos de resíduos, característicos de sua periculosidade de modo geral. Dentro do referencial teórico foram utilizadas a Lei $n^{\circ}$ 12.305/2010 que institui a PNRS (Política Nacional de Resíduos Sólidos); a resolução CONAMA no 307/2002; e a norma ABNT NBR 10004:2004, com intuito de comparar as ações do setor de tintas imobiliárias com a normatização referida.

A comparação dos dados obtidos leva à verificação de um panorama de resíduos sólidos até então imaginados. Concomitante aos resultados verificou-se a necessidade de conscientizar os sobradinhenses, de forma genérica, acerca dos riscos que os cidadãos expõem o Meio Ambiente quando não reconhecem a periculosidade que seus resíduos gerados representam; Assim sendo, tentou-se sensibilizar a população acerca dos riscos que ela expõe o meio ambiente quando descarta incorretamente resíduos de tintas e vernizes.

A partir do estabelecimento dos critérios para a coleta de dados necessitou-se identificar um panorama dos resíduos sólidos de tintas e vernizes em Sobradinho. Para isso, foi elencada a quantidade de lojas, ao total de quinze, que revendem esses materiais construtivos e, consequentemente, os intermediários do processo de produção de resíduos. Os vendedores, ao total de quinze, sendo um representante de cada estabelecimento, foram questionados quanto aos produtos vendidos. A constar, foram aplicadas questões relativas à quantidade de funcionários que a loja possui; se trabalham com tintas ecológicas; se possuem fabricação própria de tintas ou vernizes; qual o nível informacional do vendedor acerca das mercadorias sob pesquisa; e se os intermediários saberiam 
orientar seus clientes acerca do descarte de resíduos de tintas, vernizes e suas embalagens. A partir das respostas, foram estatizados gráficos para análise e comparação entre prática e teoria, do ponto de vista legislativo acerca dos resíduos construtivos civis de tintas e vernizes no munícipio em foco.

\section{Referencial Teórico}

\subsection{A periculosidade ambiental representada pelos resíduos de tintas e vernizes}

De acordo com o site Ecycle (2015), as tintas possuem solventes orgânicos, como benzeno, xileno, tolueno e cicloexano, conhecidos como VOC (compostos orgânicos voláteis) que podem apresentar alta inflamabilidade, forte odor e toxidade. No organismo humano, o mesmo site afirma que os componentes orgânicos voláteis citados acima são responsáveis por patologias, identificadas por náuseas, reações alérgicas e irritações em diversas partes do corpo. Quanto ao Chumbo, desde 2008, a concentração deste elemento químico não pode ser superior a $0,06 \%$, em peso, sendo, em concordância com a Lei № 11.762, é proibida a fabricação, comercialização, distribuição e importação de produtos fora do estipulado legalmente.

Quando se descarta incorretamente tintas no Meio Ambiente, o site Ecycle (2015) aponta como danos, a degradação da camada de ozônio por ação dos VOC; alteração do pH (potencial hidrogênico) do solo ou de águas; dificuldade do tratamento de efluentes pelo acúmulo de clorobenzeno. No contexto da incorreta destinação de tintas ao Meio Ambiente, teremos a degradação da camada de ozônio que, por consequência, aumentará a implicação do Efeito Estufa, o descongelamento de geleiras e o aumento do nível da água nos oceanos, além de causar ascendência de casos de cânceres de pele em seres humanos devido ao aumento da incidência de raios ultravioleta (ALVES, 2015, p.1-2).

Havendo a alteração do potencial hidrogênico $(\mathrm{pH})$ da água no Meio Ambiente, pode-se ter água ácida abaixo de 7 ou alcalina acima deste valor. Dependendo da natureza dos animais que habitam o manancial onde ocorra alteração do seu $\mathrm{pH}$, provavelmente haverá mortandade dos mesmos. Enquanto que, para o consumo humano, uma água que venha da natureza com o $\mathrm{pH}$ desregular, requisitará maior demanda de tratamentos químicos para ser direcionada ao abastecimento.

Por outro lado, se houver a alternância no $\mathrm{pH}$ de algum tipo de solo, dependendo de sua composição inicial, tornar-se-ia mais ácido ou alcalino em concordância com sua natureza mineralógica. Portanto, se o uso do solo fosse voltado para agricultura e estivesse ácido, dever-se-ia aplicar o processo de calagem para reuso.

Outro aspecto, às vezes deixado de lado, é o consumo energético indispensável nos processos de fabricação das tintas e vernizes. Que de acordo com a CETESB, Companhia Ambiental do Estado de São Paulo (São Paulo, 2006, p.42), muitos setores da indústria de tintas não se utilizam de maquinários com eficiência energética e empregam fontes de energia a partir da queima de óleo combustível, óleo diesel, ou gás natural. Logo, a indústria necessita controlar os gases emitidos à atmosfera, além de, essencialmente, cogitar inovações em seus sistemas produtivos que venham a empregar as fontes naturais por renováveis como o biodiesel.

A água sob outra perspectiva na indústria de tintas e vernizes, é utilizada em larga escala, seja diretamente na produção ou indiretamente, como em operações de limpeza (SÃO PAULO, 2006, p.42). Obviamente que o uso inconsciente deste recurso natural agrava o atual contexto hidrológico que vivenciamos, onde, a depender da região e da época do ano, a natureza perece nas secas ou em cheias.

Tomando como base esses exemplos sem desmerecer outros possíveis problemas que podem ser causados pelo descarte irregular de resíduos de tintas, percebe-se que medidas preventivas devem ser tomadas para que tais desestabilizações ambientais provenientes desses resíduos não se tornem comuns em nosso cotidiano.

\subsection{Normatização e Legislação aplicáveis às tintas}

Ao se direcionar um estudo sobre resíduos, pode-se facilmente identificar a PNRS (Política Nacional de Resíduos Sólidos) que é particularmente nova no contexto legislativo ambiental 
brasileiro. A Lei em questão, № 12.305 de 02 de agosto de 2010 institui a Política Nacional de Resíduos Sólidos e altera a Lei № 9.605/98. Ela não prevê apenas as destinações necessárias aos resíduos sólidos, mas essencialmente almeja a redução da produção desnecessária de resíduos. Ainda levando em consideração a Lei № 12.305/2010, mais especificadamente o artigo 13, percebe-se que os resíduos de tintas e vernizes da construção civil são classificados entre os demais, em concordância com a alínea " $\mathrm{h}$ " do Inciso I em que, quanto à origem, são resíduos da construção civil; paralelamente, em relação ao Inciso II do mesmo artigo, tais resíduos são considerados perigosos de acordo com alínea "a" devido as suas características e periculosidade à saúde e ao Meio Ambiente.

Quanto à classificação dos resíduos, toma-se como referência a norma brasileira ABNT NBR 10004:2004, em que pela maioria das tintas verifica-se características de inflamabilidade, reatividade, toxidade ou patogenicidade e, portanto, seus resíduos devem ser considerados perigosos de classe I. Porém, há de se considerar uma classificação condizente para cada especificidade de resíduo referente à tinta em questão, tomando como consideração a composição que a mesma apresenta e verificando se as características de periculosidade citadas acima são pertinentes à tinta.

Paralelamente, o Conselho Nacional do Meio Ambiente através da resolução CONAMA no 307/2002 classifica os resíduos de tintas como pertinentes aos resíduos da construção civil e para tanto, classifica tais resíduos como Classe D - perigosos da construção civil que além das tintas, incluem-se óleos, solvente e amianto. Afora isso, a mesma resolução define o que são resíduos da construção civil, quem são os geradores, transportadores, entre outros. E, em consonância com a norma, vale ressaltar que geradores "são pessoas, físicas ou jurídicas, públicas ou privadas, responsáveis por atividades ou empreendimentos que gerem os resíduos definidos nessa Resolução" (BRASIL, 2002).

Quanto à parte legislativa, é perceptível uma unanimidade referente à periculosidade que as tintas e vernizes representam à saúde e ao Meio Ambiente. Esses fatores são essenciais para uniformemente classificar os resíduos de tintas e vernizes como perigosos em todos os casos, pois, se tal classificação não pudesse ser verificada em nossa Legislação, teríamos tamanho equívoco desonesto para com o bem-estar socioambiental.

\title{
3.3 Medidas preventivas para erradicação ou redução de problemas ambientais provindos de resíduos de tintas em geral
}

\begin{abstract}
A nova Política Nacional de Resíduos Sólidos deve ser regulamentada ainda neste ano, estabelecendo o conceito de "responsabilidade compartilhada" entre fabricantes, revendedores e usuários à destinação ou reciclagem de produtos ou embalagens. O papel de cada agente só então ficará mais bem definido. Um dos pontos positivos da legislação é que, na gestão e gerenciamento de resíduos sólidos, é estabelecida a seguinte ordem de prioridade: não geração, redução, reutilização, reciclagem, tratamento dos resíduos sólidos e disposição final ambientalmente adequada dos rejeitos. (BONFIM, 2010, pg.1-2).
\end{abstract}

A partir da citação acima, em comparação com o próprio texto da PNRS, percebe-se uma preocupação ambiental para com os resíduos de tintas até então não tidos. Os paradigmas de anteriormente foram substituídos por novos a partir da regulamentação deste setor na questão ambiental, pois ficou clara a necessidade de atenção aos químicos deste setor em relação à questão ambiental.

A própria Política Nacional de Resíduos Sólidos previa o alcance de reciclagem dos resíduos em 20\% até 2015 (BRASIL, 2010). Mas esse número ainda não pode ser conferido. O importante é questionar se realmente o panorama de redução de resíduos sofreu mudanças durante o período estipulado. Quanto às tintas isso é pouco perceptível, afinal muitas pessoas utilizam-se desse material de construção e ao fim da empreitada não sabem como direcioná-lo. É devida uma generalização acerca do tratamento desses resíduos para que tal conhecimento seja disseminado entre a sociedade.

Muitas vezes surge a dúvida sobre a possibilidade de reciclagem da tinta, mas isso nem tem ocorrido devido à mistura homogênea química que torna difícil sua decomposição e separação de compostos, por outro lado, elas podem ser reutilizadas e é essa ação que tem surtido mais efeito em 
prol do Meio Ambiente. Afora isso, podem ser destinadas a aterros, desde que condizentes com sua classificação, Classe I (Ecycle, 2015).

Levando em consideração a toxidade presente nos compostos das tintas e vernizes, algumas vezes há a indicação da utilização de tintas ecológicas à tinta convencional. O problema é que um usuário comum, que desconhece a composição e diferenciação de ambas não sabe que uma tinta ecológica apenas minimiza os problemas ambientais e problemas relativos à saúde. De acordo com o site Ecycle (2015), essa tipologia de tintas é assim denominada por não requerer grandes quantidades de pigmentos à base de metais pesados, ter menor teor de VOC, não possuir odor, utilizar fontes renováveis e em abundância, apresentar baixo teor de insumos sintéticos e acima de tudo, reduzir os efeitos negativos ao Meio Ambiente. Frente a isso, não se pode considerar uma tinta ecológica como solução aos problemas ambientais causados por tintas, haja vista que mesmo ao utilizar tais tintas e houver sobras da mesma, o usuário não pode simplesmente descartá-la no lixo comum, pois ela ainda apresenta características de periculosidade pertinentes às tintas convencionais e ainda assim devem ser tratadas como resíduos perigosos de Classe I de acordo com a ABNT NBR 10004:2004.

Considerando então a Política Nacional de Resíduos Sólidos (BRASIL, 2010), o que regra a destinação correta de resíduos de tintas, é o conceito da responsabilidade compartilhada, em que todos, a incluir usuários e fabricantes possuem responsabilidade sobre o resíduo gerado a partir do produto específico. Considerando isso, a ABRAFATI (Associação Brasileira dos Fabricantes de Tintas) lançou, juntamente com a SABESP (Companhia de Saneamento Básico do Estado de São Paulo) e com apoio da ABEAÇO (Associação Brasileira da Embalagem de Aço), uma cartilha, intitulada "Pintando de Todas as cores sem prejudicar o verde" que serve de guia para que se evite o desperdício de tintas e que dê norteadores para a destinação de embalagens de tintas. Consoante à cartilha, Bonfim (2010) delimitou sumariamente no site da revista Téchne os mesmos passos, a seguir:

\footnotetext{
Calcular corretamente e adquirir apenas o volume de tinta necessário para a obra, evitando assim sobra; Armazenar corretamente a tinta e os instrumentos de pintura durante a realização do trabalho; Não guardar sobras de tintas, aproveitando-as imediatamente em outros locais (como tapumes) ou doando-as; Limpar instrumentos de pintura somente no final do trabalho; Não lavar as latas para não gerar efluentes poluidores e sim, esgotar seu conteúdo em folhas de jornal ou restos de madeira (que podem ir para o lixo comum), escorrer e raspar os resíduos com espátula; Inutilizar as embalagens no momento do descarte, evitando seu uso para outras finalidades; Encaminhar latas com filme de tinta seco para uma ATT (área de transbordo e triagem) ou para reciclagem; Guardar sobras de solventes em recipientes bem fechados, para utilização futura em outras obras, ou enviá-los para empresa de recuperação ou de incineração.
}

Através das palavras de Bonfim (2010), a ABRAFATI posiciona-se em relação aos resíduos de tintas e vernizes, as ações acima descritas e consoantes à PNRS são sumárias para a manutenção de um contexto socioambiental condizente ao esperado de uma sociedade preocupada com o seu bem-estar e com o bem-estar ambiental. Ações dúbias devem ser erradicadas para que atos errôneos não comprometam esse contexto idealizado até o presente.

\section{Resultados e Discussão}

Antes de se iniciar o processo de discussão, há de se fazer a ressalva de que o município de Sobradinho não possui um Plano de Gestão Integrada de Resíduos Sólidos (PGIRS) em vigor. O documento referenciado no presente estudo e que leva esse nome foi desenvolvido pelo IPOA (Instituto Porto Alegre Ambiental) em 2012 na gestão municipal anterior à atual. De acordo com o atual Gestor do Departamento de Meio Ambiente da Prefeitura Municipal de Sobradinho, o PGIRS tem sido utilizado como norteador a questões ambientais, mas não é legalmente vigente porque não foi aprovado pela Câmara Municipal de Vereadores, tendo em vista que ele sequer passou por uma análise dos vereadores e quiçá pela votação, devido à troca de Gestores Municipais. 
Perante isso, o município e seus cidadãos inconscientemente iniciam refutando uma preocupação para com o Meio Ambiente. Obviamente que isto não ocorre apenas nesse município, como evidencia Delongui et al. quando considera que "A região central do RS é carente de ações que envolvam os RCC. Somente a cidade de Santa Maria dispõe de um programa de gerenciamento de resíduos, o qual não é totalmente eficiente" (p.79). Por mais que Delongui et al. estejam apenas se referindo aos RCC (Resíduos da Construção Civil), ainda pode-se notar um determinado descaso dos gestores municipais quantos aos resíduos de uma maneira geral.

Além do PGIRS não estar em vigor em Sobradinho, ele encontra-se desatualizado, pois nele consta um depósito irregular de resíduos da construção civil, mais especificamente, de RCD (Resíduos de Construção e Demolição), entre outros materiais, como restos de podas, nomeado por "bota fora", localizado acima do Parque Municipal da FEJÃO, datado de 2012 que está evidenciado na Figura 1. Atualmente esse depósito foi desativado e os resíduos que lá constavam foram encaminhados para locais de aterro, pois continham em predomínio, restos de alvenaria e concreto, materiais reconhecidos em canteiros de obra por entulhos, como se evidencia na Figura 2.

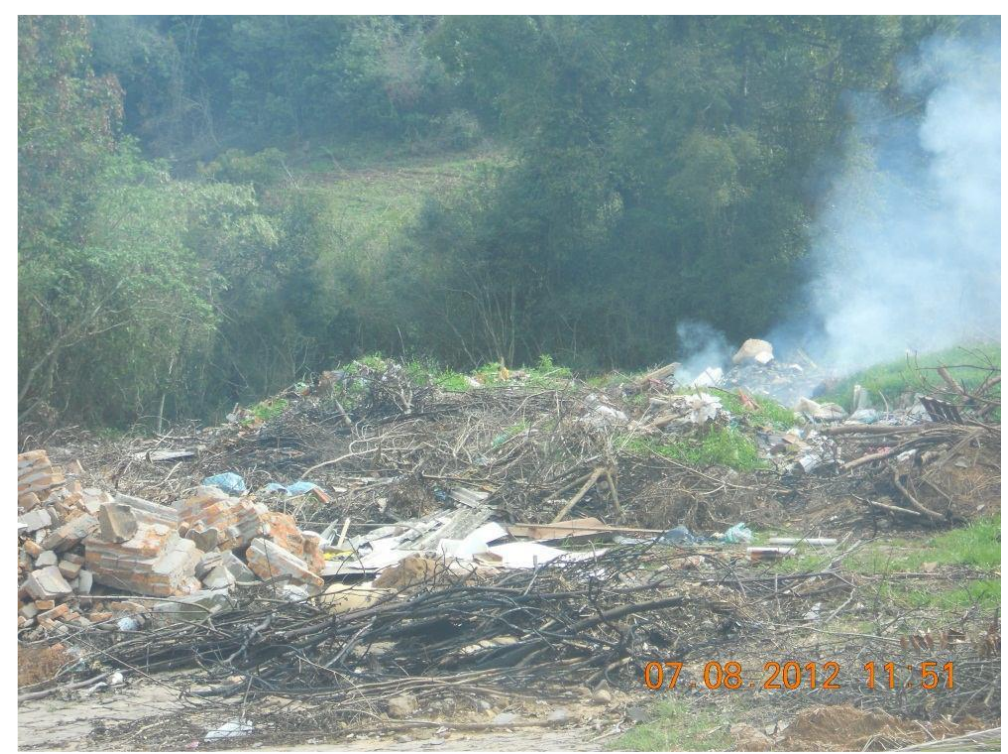

Figura 1 - Antiga área irregular de bota fora Fonte 1: IPOA

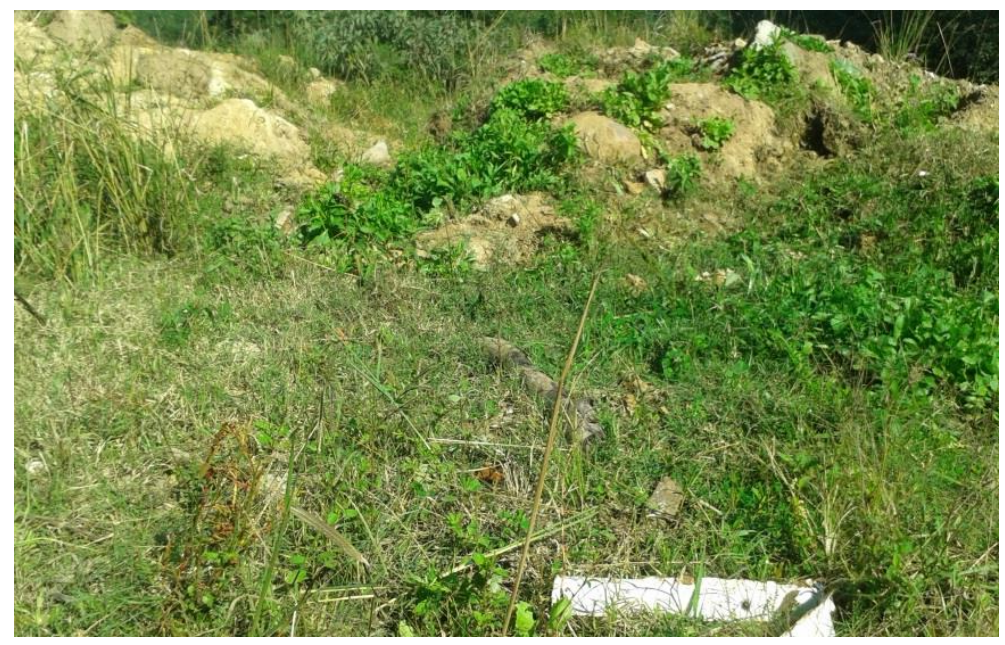

Figura 2 - Atual área do antigo bota fora irregular Fonte 2: Autor

Dentre outros parâmetros, percebe-se que Sobradinho não possui uma Área de Transbordo e Triagem (ATT), o que dificulta alguns trâmites ambientais quanto à reciclagem. A necessidade de implantação de uma ATT no município já havia sido verificada em 2012 pelo IPOA e consta como 
uma prioridade a longo prazo no PGIRS de mesmo ano para ocorrer entre 4 e 8 anos. A ação de implantação de uma ATT ainda não foi constada no município, devido a causas externas como a possível falta de verba ou a não legalização do próprio PGIRS. Essa não implantação de uma Área de Transbordo e Triagem soa como mais um descaso ambiental do município e de seus cidadãos.

No antigo "bota fora" do Parque da FEJÃO, não haviam sido percebidos resíduos de tintas ou de embalagens destas, mas poderiam ser percebidas algumas ferragens. Provavelmente, os resíduos de materiais de pintura, no caso das embalagens eram reaproveitados de outra forma ou encaminhados para reciclagem. Por conseguinte, o modo como tem sido feito o descarte de tintas e de suas embalagens em Sobradinho, é constante. Ou seja, de forma empírica, as pessoas tendem a reaproveitar as sobras de tintas em outros locais não planejados para pintura até a verificação de sobra; as latas têm sido encaminhadas para reciclagem ou em casos mais específicos, reutilizadas na própria residência para armazenagem de outros produtos, ação essa que requer uma lavagem da embalagem e por consequência, a contaminação de recursos hídricos a depender da composição da tinta e do modo de lavagem, quando, geralmente, o líquido vai para qualquer meio de descarte sem o devido tratamento.

Supondo que os geradores de resíduos sólidos necessitam adquirir produtos para geração do resíduo, foi realizada uma pesquisa de levantamento nas lojas do município de Sobradinho para aferir o quanto seus vendedores saberiam nortear os geradores acerca de resíduos construtivos de tintas e vernizes. Em seguida foi verificada a quantidade de lojas que trabalham com tintas imobiliárias em Sobradinho, em consonância a Figura 3, pode-se perceber que das 15 lojas que vendem tintas imobiliárias, 7 são de redes que além de venderem materiais construtivos, vendem móveis e eletrodomésticos; 6 são lojas de materiais construtivos somente; e 2 são lojas especializadas apenas na venda de tintas e vernizes, sendo que entre elas, 1 possui fabricação própria de tintas.

Mais afrente, percebeu-se que as Lojas de Redes, são aquelas que menos denotam conhecimento sobre os produtos referentes a tintas e vernizes, provavelmente pela diversidade de produtos comercializados em suas lojas, em virtude disso, a carga cognitiva requerida pela multiplicidade de produtos faz com que os vendedores negligenciem alguns e deem ênfase naqueles mais requeridos pelos compradores, havendo pouca procura por tintas em tais estabelecimentos, há também pouca preocupação com mesmos por partes dos lojistas e funcionários.

Mais adiante, foi verificada as lojas sobradinhenses que disponibilizam cursos a seus funcionários sobre tintas com intuito de perceber quanto os vendedores denotam de conhecimento acerca do assunto e, se, têm noção das consequências que o descarte irregular de tintas ou suas embalagens geram no Meio Ambiente. Pode-se perceber que apenas duas lojas disponibilizaram cursos a seus funcionários, vendedores na maioria dos casos. Quando citados, tais cursos não são exatamente disponibilizados pelas lojas em si, mas sim pelas fábricas das tintas que possuem venda de seus produtos nessas lojas. Todavia, percebeu-se que nas lojas onde foram ofertadas tais formações aos funcionários, o nível informacional sobre tintas e em especial, sobre as consequências ambientais de seus resíduos foi superior àquelas onde não havia sido ofertada nenhuma exposição informativa acerca de tintas e vernizes.

Nas entrelinhas do questionário, pode-se verificar que a loja com fabricação própria de tintas não disponibiliza cursos de formação a seus colaboradores, em contraponto, eles detêm tanto conhecimento empírico sobre seus produtos que não ficam em desvantagem quando em comparação aos colaboradores de outras lojas, como as de materiais construtivos.

Tomando em consideração a Figura 4, nota-se que a maioria dos questionados não soube responder o que se fazer com resíduos de tintas, enquanto isso, trinta e três por cento responderam que os resíduos deveriam ser armazenados em local seco e arejado para uma possível utilização futura; vinte por cento, citou o reaproveitamento como destinação correta do resíduo e, apenas um indivíduo, representante de uma loja de rede indicou a abertura de um buraco no quintal e enterro desse resíduo para não geração de um problema ambiental.

A partir dos resultados obtidos, expostos na Figura 4, notou-se que a maioria dos vendedores de tintas sobradinhenses sabe como orientar seus clientes quanto ao descarte de resíduos de tintas, tendo em vista que citaram o armazenamento ou o reaproveitamento da tinta em outro local particular ao planejado inicialmente, se somado as porcentagens ter-se-á uma totalidade de $53 \%$ como indicação 
correta de destinação desses resíduos. Essas orientações, às vezes tomadas de modo empírico pelos vendedores estão de acordo com a resolução CONAMA no307/2002 que preconiza o armazenamento, transporte e destinação em conformidade a normas técnicas específicas para resíduos Classe D, no caso, resíduos de tintas e vernizes, bem como estão em conformidade com as proposições feitas pela ABRAFATI, a reutilização da tinta em outro lugar não planejado até a percepção de resíduo.

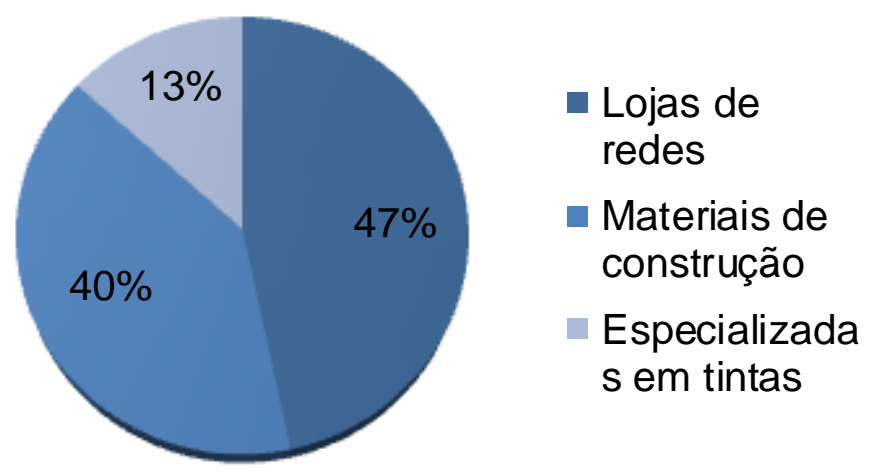

Figura 3 - Gráfico quanto aos tipos de lojas que revendem tintas e vernizes em Sobradinho

Quanto ao que se expõe na Figura 5, evidencia-se uma equidade de opiniões tanto para aqueles que não souberam o que responder, tanto por não denotarem conhecimento sobre o assunto como por não terem vivenciado uma algo similar ao hipotético do questionamento, como para aqueles que indicariam a reutilização, reciclagem ou deposição em lixo comum.

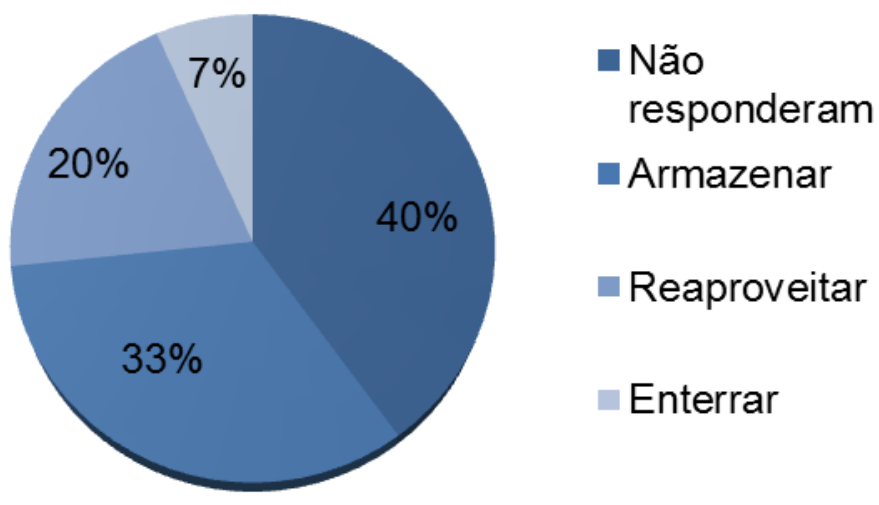

Figura 4 - Gráfico quanto à Destinação de tintas e vernizes

Embora 20\% dos questionados tenha indicado o descarte de embalagens de tintas em lixo comum, de acordo com a ABRAFATI, as embalagens deveriam ser encaminhadas a uma ATT, ou a pontos de entrega voluntários (PEV) ou ainda, a sucateiros licenciados. O problema é que em Sobradinho não há ATT, nem PEV, restando apenas o encaminhamento a sucateiro licenciado, havendo muitos sucateiros, somente um no município é licenciado. Julga-se, comumente que o descarte no lixo comum solucionaria o problema, o que não seria inteiramente correto, mas seria menos agressivo ao Meio Ambiente, tendo em vista que os resíduos são recolhidos durante a semana pela Prefeitura Municipal e encaminhados ao aterro sanitário do município de Minas do Leão. Por consequência, tais resíduos 
não seriam poluidores em outros locais aleatórios, como o arroio Carijinho, alvo fácil de deposição irregular de resíduos sólidos do município.

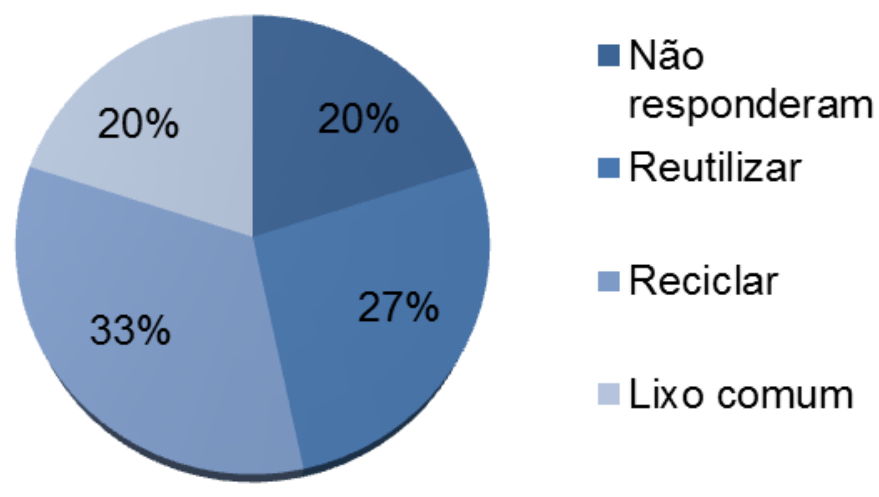

Figura 5 - Gráfico quanto ao descarte de embalagens de tintas e vernizes

Sob outra perspectiva, aqueles que indicariam a reutilização, não deixam de estar corretos, mas negligenciam a deposição dos resíduos de tintas das embalagens que escoam e terminam por contaminar recursos hídricos porque após as lavagens, os resíduos líquidos não são designados ao tratamento de esgoto, tendo em vista que Sobradinho não possui linhas de tratamento de esgoto, provavelmente, todas as "reutilizações" de embalagens de tintas descarregam o meio ambiente de um resíduo sólido, mas sobrecarregam o mesmo com resíduos líquidos, os quais contaminam recursos hídricos, inconscientemente.

Aos que indicaram a reciclagem como processo de descarte de embalagens de tintas, estão corretos, mas refutam a ideia de que em certos momentos estão destinando tais resíduos a catadores não licenciados que não denotam conhecimento sobre a reciclagem de tais embalagens e favorecem às mesmas, um processo de reciclagem comum. Deve-se destacar que a lata de aço pode ir à reciclagem infinitas vezes (ABEAÇO, 2006, p.12) e, por isso, deve ser uma ação a ser adotada em nosso cotidiano, pois poupa a Natureza de uma demanda grandiosa de energia ou da extração de novas matériasprimas. Por outro lado, na pior das hipóteses quanto ao descarte de embalagens, se a lata de aço fosse descartada no Meio Ambiente, a ABEAÇO (2006, p.12) afirma que essa lata tende a se decompor e retornar ao estado de minério de ferro em um período de cinco anos. Fato que não pode ser esperado de outros materiais empregados em embalagens, como o plástico, por exemplo. Porém, a casualidade da não tão grande agressividade ambiental por parte da embalagem não redime a sociedade de importar-se corretamente com a mesma e por isso, prevalecer-se e descartá-la incoerentemente em quaisquer paragens.

Para aqueles que não souberam responder, percebe-se a necessidade de um curso, ou uma ação de educação ambiental que vise à emissão de informações acerca da periculosidade que as tintas representam ao Meio Ambiente quando descartadas incoerentemente. Tais ações poderiam vir a ser tomadas pelos próprios lojistas, ou em outros casos, pelos fabricantes das tintas, haja vista que de acordo com a PNRS, não é apenas o consumidor final que necessita preocupar-se com seus resíduos, mas todos aqueles envolvidos no processo de produção e utilização devem estar cientes e voltados para promoção de uma sociedade precavida com o futuro do Meio Ambiente e da própria sociedade.

Por fim, os questionados foram solicitados quanto à venda de tintas ecológicas em suas lojas. Observando a Figura 6, nota-se que 7\% não soube responder se trabalha ou não com tintas ecológicas, isso demonstra o descaso por parte dos vendedores para com as mercadorias, que por consequência, mostra-se um descaso para com o cliente, porque em dados momentos o indivíduo pode ir à loja para requerer informações e elas acabam não sendo dadas, ou quando dadas, são imprecisas. Essa imprecisão pode também ser averiguada quando o cliente solicita ao vendedor informações acerca de como descartar resíduos de tintas ou suas embalagens, como visto nos gráficos anteriores, não obstante, a informação equívoca tende a gerar uma carga residual desnecessária ao Meio Ambiente, 
tendo em vista que o indivíduo leigo, não sabe como proceder para boa manutenção ambiental e termine por contrapor isso através das informações inexatas tomadas junto às lojas pesquisadas.

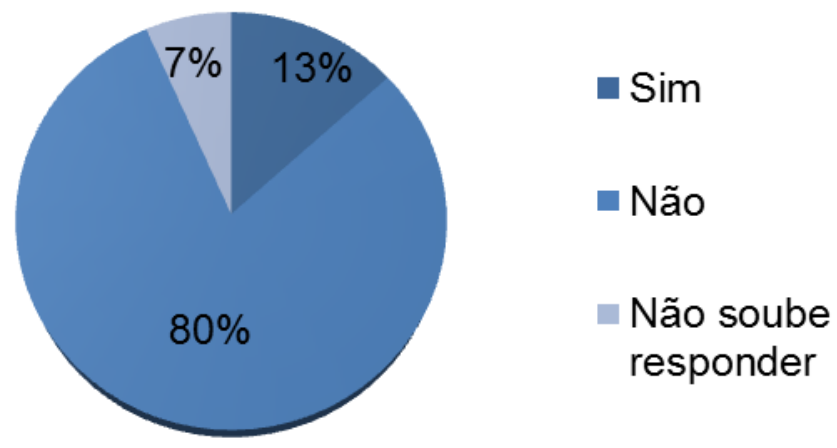

Figura 6-Gráfico quanto ao número de lojas que trabalham com tintas ecológicas

Em contrapartida, a maioria dos pesquisados afirmou não ter em suas lojas linhas de tintas ecológicas. Embora se saiba que a tinta ecológica não livra o Meio Ambiente de perdas energéticas e resíduos, elas tendem a utilizar menos energia em sua produção ou a utilizar fontes renováveis, o que apenas minimiza os danos causados ao Meio Ambiente e pela primazia, estaria contribuindo para obtenção de uma sociedade mais consciente da magnitude de sua Pegada Ecológica e preocupada com seu habitat.

Uma pequena parcela indicou trabalhar com tintas ecológicas, isso foi devido a uma marca de tintas em especial, citada por ambas, que tem buscado reduzir ou substituir os compostos orgânicos voláteis (VOC) de seus produtos por outros menos agressivos ao Meio Ambiente. Outra ação tomada por essa fábrica foi a substituição do solvente pela água, ou seja, toda linha de tintas passará a ser a base de água, um recurso natural pertinente a um ciclo que tende a retornar a seu estado natural sem muitos danos ambientais.

Ante aos gráficos expostos acima, verificou-se a necessidade de implantar ações sob as vistas da Educação Ambiental para que ideias tomadas como corretas em relação aos resíduos de tintas e vernizes sejam transformadas. Partindo da verificação do conhecimento acerca de tintas por parte dos colaboradores das revendas, projeta-se um conhecimento tido por parte de todos os sobradinhenses e, percebe-se a obrigatoriedade de modificar o senso comum que se têm acerca de tintas e seus resíduos. Devem ser tomadas ações que reduzem o desperdício desses materiais construtivos e que consequentemente promovem a sustentação de uma sociedade voltada para o desenvolvimento social sem ferir o Meio Ambiente.

\section{Conclusões}

O panorama de resíduos sólidos do munícipio de Sobradinho nada mais é que o fruto de uma negligência da população e de gestão aliado à falta de informação. Bem por isso, presenciamos descarte irregular não apenas dos resíduos de tintas e vernizes sobre o Meio Ambiente, pois não se tem uma cultura desenvolvida de causa e consequência e muitas ações são realizadas sem a percepção de sua futura consequência.

É importante à sociedade sobradinhense que não descarte restos de tintas em redes de escoamento, recursos hídricos ou sobre o solo. No primeiro dos casos, os efeitos de enchentes seriam acrescidos devido à carga de sólidos, embalagens, em tais vias; no segundo e terceiro, ter-se-ia a contaminação de recursos naturais que podem ser utilizados no futuro e solicitarão descontaminação para seu uso. Efeito similar pode ser verificado no arroio Carijinho, via hídrica que corta a cidade, onde há alto grau de contaminação das águas devido ao despejo de sólidos irregular. 
Com intuito de conscientizar a população sobradinhense, compôs-se uma carta aberta ao jornal local, elencando ações a serem tomadas como corretas quanto ao descarte de resíduos de tintas, vernizes e suas embalagens. No texto, pode-se verificar sumariamente o que tais ações trariam de benefício ao Meio Ambiente, à sociedade e a Sobradinho. Ainda, percebe-se a explanação das mesmas como exemplificação de sua não ocorrência, os malefícios que trariam ao Meio Ambiente, perceptível na atualidade, o já citado arroio Carijinho. No ponto de vista educativo ambiental a publicação deste texto é apenas um pontapé no princípio da sensibilização da sociedade sobradinhense para com o Meio Ambiente.

Mesmo assim, também se verifica a necessidade de incentivar o Departamento de Meio Ambiente a promover ações que visem melhorias no panorama de resíduos sólidos e a ele foi enviada uma carta solicitando melhores vistas com este propósito. Não é a intenção criticar o atual trabalho, mas instigar a melhoria dos afazeres com intuito de modificar a perspectiva dos sobradinhenses sobre as consequências de suas ações sobre o Meio Ambiente.

Tomando como base as pesquisas de levantamento e bibliográfica realizadas para composição acerca dos resíduos de tintas e vernizes no município de Sobradinho, percebeu-se que esta comuna sul-rio-grandense carece de explanações acerca de resíduos sólidos, de uma maneira geral. Em particularidade aos resíduos de tintas e vernizes e suas embalagens, cabe algumas ações de cunho educativo ambiental, pois o que se verifica junto aos colaboradores de revendas desses materiais construtivos na área urbana sobradinhense é uma deficiência conceitual e informacional.

Quebrar os paradigmas empíricos que comprometem a sustentação de uma sociedade voltada ao desenvolvimento socioambiental sem perdas a quaisquer dos lados, torna-se a base para construção dessa atual utópica sociedade. Por consequência, modificar as ideias tidas como corretas acerca de tintas e resíduos em Sobradinho é de fundamental importância para redução de pequenos impactos ambientais causados inconscientemente pela sua população no tocante às tintas e vernizes.

Em contrapartida e igualitariamente, os gestores municipais devem dar melhores vistas ao Meio Ambiente de um modo geral. Pois bem se percebe que muitas tarefas em outras áreas tem sido feitas com êxito, a exemplificar, melhorias na área da assistência social, obras, saúde ou educação, ações essas de caráter prioritário para o desenvolvimento de uma boa sociedade, porém, o Meio Ambiente nem sempre tem estado em evidência, e por isso, tem permanecido em segundo plano. Logo, as ações cotidianas provindas das gestões, como o recolhimento de lixo são importantes para a fundamentação dessa dita "boa sociedade", mas afazeres que saem do comum e tirem seus populares da monotonia também favorecem a promoção social e em outros casos, o cuidado ambiental para promoção daquela sociedade idealizada anteriormente, haja vista que não pode haver uma boa sociedade sem um bom ambiente. Para exemplificar tais ações de cunho ambiental a serem esperadas pelos gestores municipais, entra o incentivo de catadores licenciados, a legalização de um Plano de Gestão Integrada de Resíduos Sólidos atualizado e condizente com as reais necessidades populacionais, como a implantação de uma Área de Transbordo e Triagem que promova não apenas o recebimento, destinação e tratamento de resíduos de tintas e vernizes, mas de outros resíduos tanto quanto tóxicos e perigosos ao Meio Ambiente, como os eletrônicos.

O prevalecimento do indivíduo sobre o Meio Ambiente deve ser erradicado, pois não apenas em Sobradinho, mas em outros municípios afora, percebe-se o descaso populacional para com o Meio Ambiente. No município pesquisado, pode-se afirmar que a população não tem reagido coerente às ações benéficas ao ambiente porque ainda não estão perceptíveis os danos que suas ações cotidianas tendem a causar, tanto ao Meio Ambiente como a si própria. Cabem então, campanhas que conscientize a sociedade sobradinhense sobre os riscos aos quais ela mesma tem se exposto em relação ao descaso socioambiental.

Rever conceitos, modificar ideias, ou melhor, aprimorar a cultura de uma sociedade não é tão simples quanto escrever sobre isso. Educadores ambientais devem promover práticas de conscientização junto aos gestores municipais com intuito de aperfeiçoar o cerne cultural de nossa atual sociedade. A caráter da sociedade sobradinhense, dever-se-ia objetar a explanação de perigos ambientais resultantes de afazeres cotidianos, pois se percebe um elevado grau de contaminação em 
nosso arroio Carijinho devido a ações inconscientes de descarte de resíduos sólidos de uma forma generalizada.

No tocante aos resíduos de tintas, deve-se informar aos sobradinhenses o que se fazer com esses materiais. Reaproveitá-los em outros locais é uma ótima solução, mas doá-los a quem esteja necessitando de uma pintura para manutenção do substrato de sua residência deixa de ser apenas uma boa prática ambiental e passa a ser uma excelente prática socioambiental, pois além de preocupar-se com o Meio Ambiente, o doador estará também se preocupando com o seu próximo.

Quantos às embalagens, o descarte em área urbana pode ser facilitado quando destinado ao recolhimento de lixo, promovido em todos os bairros em mais de um dia durante uma semana. Em outros casos, eles podem ser destinados ao reciclador licenciado que busca na residência a partir de um simples telefonema. Mas de forma nenhuma, a embalagem deve ir à Natureza, mesmo que no caso de aço, decomponha-se. Tal ação evidencia o descaso da sociedade para consigo mesma e para com o contexto em que se insere, o Meio Ambiente.

\section{Referências}

ASSOCIAÇÃO BRASILEIRA DA EMBALAGEM DE AÇO. As verdades e as mentiras sobre a lata de aço. São Paulo: ABEAÇO, 2006, p.12.

ASSOCIAÇÃO BRASILEIRA DE NORMAS TÉCNICAS. NBR 10004: Resíduos Sólidos Classificação. Rio de Janeiro: ABNT, 2004.

ASSOCIAÇÃO BRASILEIRA DOS FABRICANTES DE TINTAS. Resíduos Sólidos. Disponível em: < http://www.abrafati.com.br/programas/residuos-solidos/>. Acesso em: 15 jun. 2015.

ALVES, Líria. Como é destruída a camada de ozônio? In: BRASIL ESCOLA. Disponível em: $<$ http://www.brasilescola.com/quimica/como-destruida-camada-ozonio.htm>. Acesso em: 20 jun. 2015.

BONFIM, Gisele. Tintas e Solventes: O que fazer com embalagens/latas com restos de tintas, solventes e vernizes? In: TÉCHNE. Disponível em: < http://techne.pini.com.br/engenharia-civil/162/40perguntas-reciclagem-destinacao-de-residuos-286747-1.aspx>. Acesso em: 15 jul. 2015.

BRASIL. Conselho Nacional do Meio Ambiente. Resolução CONAMA no 307: Estabelece diretrizes, critérios e procedimentos para gestão dos resíduos da construção civil. Diário Oficial [da] República Federativa do Brasil. Brasília, DF, 17 jul. 2002. no 136.

BRASIL. Lei n. 11.762 de $1^{\circ}$ de Agosto de 2008. Fixa o limite máximo de chumbo permitido na fabricação de tintas imobiliárias e de uso infantil e escolar, vernizes e materiais similares e dá outras providências. Diário Oficial [da] República Federativa do Brasil, Brasília, DF, 1ํo ago. 2008. Disponível em: <http://www.planalto.gov.br/ccivil_03/_ato2007-2010/2008/lei/111762.htm>. Acesso em: 15 jun. 2015.

BRASIL. Ministério do Meio Ambiente. Lei n. 12.305 de 2 de Agosto de 2010. Institui a Política de Resíduos Sólidos; Altera a Lei no 9.605, de 12 de fevereiro de 1998; e dá outras providências. Diário Oficial [da] República Federativa do Brasil, Brasília, DF, 2 ago. 2010. Disponível em: $<$ http://www.planalto.gov.br/ccivil_03/_ato2007-2010/2010/lei/112305.htm>. Acesso em: 15 jun. 2015.

BRASIL. Ministério do Meio Ambiente. Política Nacional dos Resíduos Sólidos. In: MINISTÉRIO DO MEIO AMBIENTE. Disponível em: < http://www.mma.gov.br/pol\%C3\%ADtica-deres\%C3\%ADduos-s\%C3\%B3lidos>. Acesso em: 15 jul. 2015. 
DELONGUI, Lucas. et al. Panorama dos Resíduos da Construção Civil na Região Central do Rio Grande do Sul. Teoria e Prática na Engenharia Civil. Rio Grande, RS, n.18. p.71-80. nov. de 2011.

INSTITUTO PORTO ALEGRE AMBIENTAL. Plano de Gestão Integrada de Resíduos Sólidos: Prefeitura Municipal de Sobradinho/RS. Porto Alegre, dez. de 2012.

SÃO PAULO. Guia Ambiental Tintas e Vernizes - Série P+L. São Paulo: CETESB, 2006. p.42. 